\title{
Modelling a Battle: Looking Beyond Numbers
}

\author{
$\underline{\text { S. Kravchuk }}^{\text {a }}$ and O. Pushkarov ${ }^{b}$ \\ ${ }^{a}$ Maritime Division, Defence Science and Technology Group, Edinburgh, South Australia \\ Email: Sergiy.Kravchuk@dst.defence.gov.au \\ ${ }^{b}$ School of Mechanical Engineering, University of Adelaide \\ Email: oleksandr.pushkarov@adelaide.edu.au
}

\begin{abstract}
The history of warfare shows that victory of the stronger side is not guaranteed even if the force balance is heavily in its favour. The expected outcome of analytical or computational models would be centred somewhere around victory for the stronger side being decisive, however presenting some small but realistic chance for the weaker side victory. This uncertainty reflects our ignorance regarding critically important information.
\end{abstract}

We suggest that analysing available information on a historical battle outcome may provide enough data to quantify these uncertainties.

We advocate that such analysis must involve three important steps: studying available historical evidence, building an analytical or semi-analytical model of the action, and running simulation games. We would like to emphasise that simulation games are a critically important part of this procedure that are used to weight competing hypotheses against each other and against reality.

We illustrate this thesis with analysis of a historical amphibious operation at Petropavlovsk in 1854. The Anglo-French assault forces outnumbered the defenders in the ratio 2:1 but still suffered a crushing defeat.

From the available historical data we were able to isolate a reason for Allied failure and define it to the point where it became possible to introduce it into a simulated battle. We concluded from an analysis of witness accounts that frequent cases of friendly fire between the Allies could be the main cause of the force defeat. We considered the action as two battles: one between the Allies and Russian troops, and the second between the British and French troops. We tested our hypothesis with an analytical attrition model as well as with a series of war games. The final outcomes of both methods were close to the historical outcome.

The simulation games we played helped us to see several directions of further inquiry: why these friendly fire episodes were so frequent and so devastating, and why the Allied commanders chose the particular plan of attack. We believe that properly designed simulation games are well-suited to investigate these problems, which will be topics for our future research.

Keywords: $\quad$ War games, simulation, combat models 


\section{INTRODUCTION}

Numerical strength and quality of forces are crucial factors determining the outcome of combat. Perhaps the first military thinker who put it in writing in unambiguous terms was Carl von Clausewitz. In his book "On War" he wrote that "superiority of numbers admittedly is the most important factor in the outcome of an engagement as long as it is great enough to counterbalance all other contributing circumstances" (Clausewitz 1984). The first formal treatments of this thesis are due to Lanchester and Osipov in 1914 and 1915, respectively (Hembold and Rehm 1995, Lanchester 1995). The idea turned out to be extremely fruitful, giving a start to the whole new area of theory of combat (Taylor 1983, Dupuy 1992, Fowler 1995).

Being a professional military officer von Clausewitz clearly articulated that numerical strength is not the only factor that contributes to the outcome; quality of the opposing forces and circumstances of the battle are also of importance for the final outcome. History tells us that having all the advantages does not necessarily guarantee a victory. On many occasions historians have argued that weaker sides have still had a small but realistic chance of avoiding defeat, and in some cases the weaker side actually won the battle. To account for the complexity of a fighting force as a system and the uncertainties this complexity brings to the battle dynamics von Clausewitz introduced a concept of friction but clearly stated that these "frictions" cannot be quantified: "This tremendous friction ... brings about effects that cannot be measured, just because they are largely due to chance".

Following von Clausewitz, we suggest to treat uncertainties as an umbrella concept for our ignorance regarding critically important information about the forces in conflict. We show, however, that analysing the available information on the battle outcomes may provide enough data to quantify these frictions, at least partially. Knowing and quantifying them upfront would put the expected outcome closer to reality - or at least point to critical factors which determine the outcome in a particular battle.

We believe that such analysis must involve three important steps: studying available historical evidence, building an analytical or semi-analytical model of the action, and running simulation games to weight competing hypothesis against each other and also to get insight into the battle dynamics. This approach is similar to some extent to P. Sabin's methodology of reconstructing ancient historical battles (Sabin 2007), but it differs in some principal points: we aim to understand reasons behind the battle outcome, not to reconstruct the battle as such; and to achieve this goal, we explicitly use an analytical model as a precursor to the simulation step, thus defining focus for the games to follow.

We illustrate this thesis with analysis of a historical amphibious operation at Petropavlovsk in 1854. The Anglo-French assault forces outnumbered the Russian defenders in the ratio 2:1 but still suffered a crushing defeat. From the available historical data we were able to isolate the likely reason for Allied failure and quantify it to the point where it became possible to introduce it into both an analytical model of the battle and into a simulated battle.

The rest of the paper is organised as follows: Section 2 provides a brief overview of the historical battle. Section 3 presents analytical treatment of the battle using a simple attrition model. Section 4 presents results of the simulation games. Section 5 discussed the obtained results of simulation games and compares them with the analytical treatment and historical data. Section 6 summarises the findings and presents conclusions from our work.

\section{ACTION AT PETROPAVLOVSK 1854}

Petropavlovsk was a Russian outpost and small port on the Kamchatka peninsula in the Northern Pacific. By August 1854 the garrison included around 1000 able men (regular infantry, gunners, sailors, and volunteers) and had 93 guns including those on one frigate and one transport ship. The Allied squadron which attacked Petropavlovsk in 1854 consisted of six ships, totalling 202 guns and around 2200 sailors and marines.

There were two attempted Allied landings, on 31 August and 4 September 1854 (dates according to the British ship logs). The first attempt was aborted for some unclear reasons; the second attempt, which is of interest for our research, ended in a crushing defeat of the Allies (Grainger 2008, Rath 2015).

A detailed description of the battle was given by Stone and Crampton (1985). As this is not a well-known battle, for the reader's convenience the course of action is outlined below and is also shown in Figure 1.

The Allied landing party consisted of 676 marines and sailors (Zavoiko 1954) (some sources give the total number as 700 men), divided into five units: two British, two French, and one combined. They were opposed by around 300 Russian troops split into ten separate small detachments, each led by an officer. Early in the morning the Allied ships bombarded two Russian batteries (№3 and №7) into silence, so the assault force 
landed unopposed. The remaining Russian gunners withdrew from the ruined batteries. On securing the beachhead near battery №7 the Allied landing party separated into three big groups; one climbed Nikolski Hill aiming for an elevated position around the summit, the second went along the beach to capture the hill summit from the south, and the third went along the road to the town of Petropavlovsk. Soon it bumped into battery №6 and turned right to Nikolski Hill.

Once the Allies succeeded in capturing the top of the hill, they were in a command position able to use effectively their longer-range rifled muskets to shoot approaching Russian troops from a distance. The defenders of Petropavlovsk were in a dire situation. Yet somehow the Russian troops were able to climb the hill under fire without unbearable casualties, and soon they drove the Allies back to the landing site. Those who made it for the boats rowed away, still under the musket fire of the Russian troops.

Out of 202 men lost by the Allies in action (killed, missing, or wounded) the British casualties amounted to 107 men, and the French lost 95 men (The Affair at Petropavlovski 1855). The Russians casualties were 96 men killed or wounded in this battle (Zavoiko 1954).
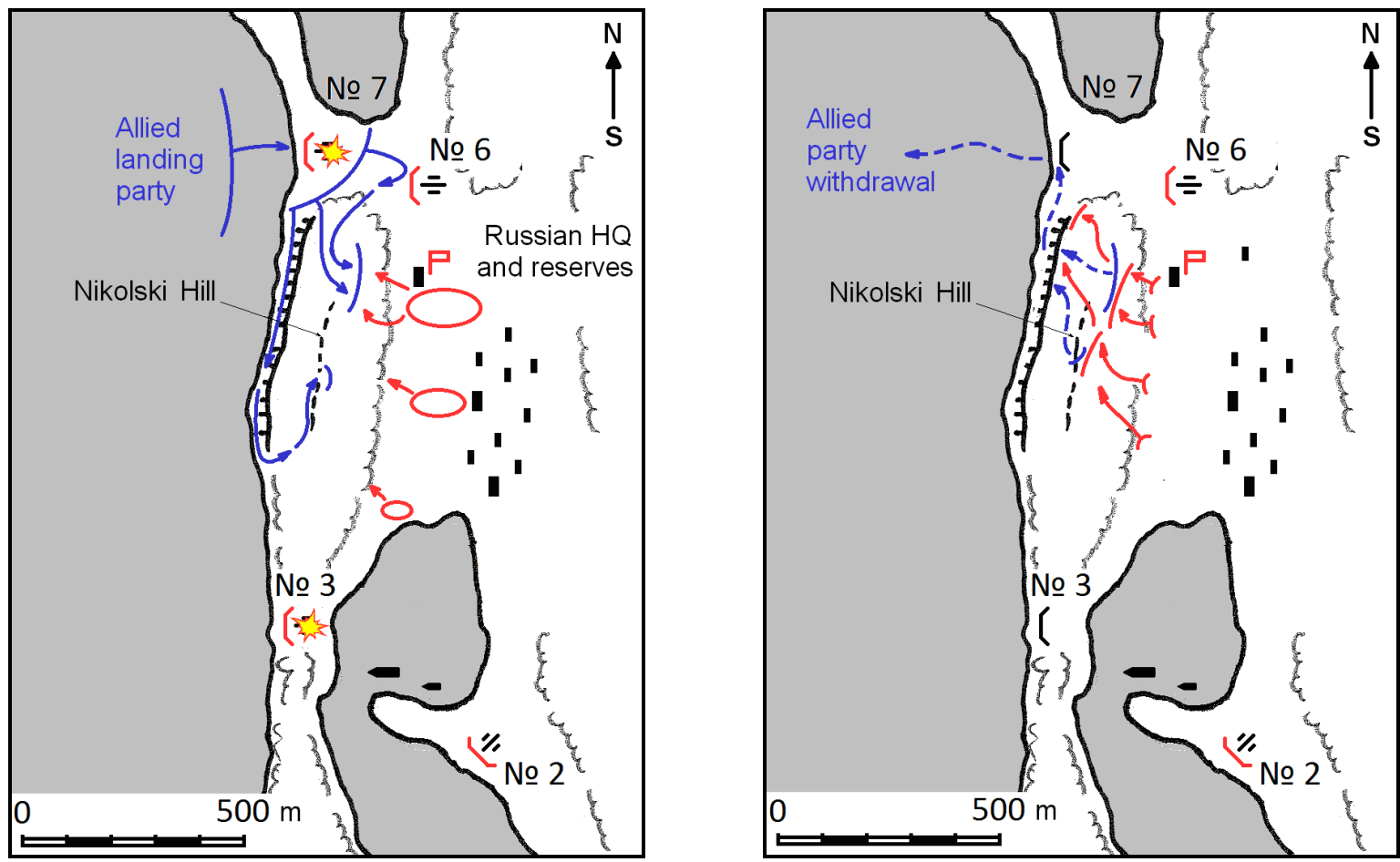

Figure 1. Action at Petropavlovsk 4 September 1854. Left: the initial phase of the battle; right: the final phase of the battle. Numbers indicate Russian batteries. Batteries №3 and №7 were silenced before the landing commenced.

\section{ATTRITION ANALYSIS}

The losses of the Allies in this landing compared to the Russians appeared to be uncharacteristically high.

The Allied party landed unopposed as all Russian soldiers retreated from ruined battery №7 to the town. Apart from a brief encounter with battery №6 the Allies met no resistance in occupying the Nikolski Hill summit. The subsequent battle was essentially a meeting engagement; it is true that Allied movement and command was severely impeded by the rough terrain, but the same applies to the Russians. Despite being outnumbered in the ratio $2: 1$, the Russian troops managed to inflict twice as many casualties as losses they suffered.

Such outstanding performance cannot be explained by superior Russian arms as the Allies were armed with rifled muskets, while Russians still used the old smoothbore muskets with a shorter effective range. Neither can it be explained by better training nor by good preparation of the defensive positions as the Russians did not have enough time for that: for example, battery №6 was not even finished and did not have enough trained gunners, so it could fire only four guns out of ten (Zavoiko 1954). Nor can the Russian victory be explained by higher morale of the troops: it became critical only after the Russians managed to inflict 
numerous casualties to the Allies, so obviously the winning factor worked well before the Allies became unsteady and fled the battlefield.

It is true that Allies suffered one-sided heavy casualties at the final stage of the battle when boarding the boats, but at the same time Russians suffered one-sided heavy casualties at the beginning of the battle from Allied bombardment (both Russian officers wounded in the battle were hit by the ships' gunfire), so the detailed consideration, even if it was possible, unlikely would change significantly the relative combat performance.

We put forward a conjecture that the Russian victory was due to extremely poor cooperation between British and French detachments during the battle which manifested in frequent cases of friendly fire. Witness accounts from both British and French sides mention cases of casualties from friendly fire in dense bushes on the slopes of Nikolski Hill (du Hailly 1858, Ashcroft 1965). Surprisingly, the French writer claimed that Russians were dressed in red shirts and looked like British, while the British complained that Russians wore big coats and looked like French. Remarkably, no Russian witness complained about difficulties in identifying friend or foe. Even more remarkably, at least one episode seemingly resulted in a hand-to-hand combat between the French and the British troops (du Hailly 1858, Seymour 1911, Fesun 1860) despite uniforms not being obscured by foliage and voices clearly heard.

Based on this finding we suggested a hypothesis that friendly fire was the decisive factor of the Allied defeat and Russian victory. We assumed that there were two battles on Nikolski Hill, one was between the Russian and Allied troops, and the second was between French and British troops. In our simple analytical model we assumed that in each of these two battles the opposing forces were even and calculated expected losses of each side using Russian losses as a baseline. The results are presented in a table below.

Table 2. Analytical model of friendly fire effect on Allied casualties

\begin{tabular}{|l|c|c|c|}
\hline & British & French & Russian \\
\hline Initial strength & 338 & 338 & 300 \\
Losses from enemy action & 48 & 48 & 96 \\
Losses from friendly action & 60 & 60 & 0 \\
Total losses & 108 & 108 & 96 \\
Historical losses & 107 & 95 & 96 \\
\hline
\end{tabular}

The analytical results for the British and French losses were surprisingly close to the historical data. We took this as a confirmation of our reasoning on the role of friendly fire in the battle outcome. Moreover, we could now quantify this factor by assigning probability of engaging a friendly unit approximately equal to 0.5 .

\section{SIMULATION GAMES}

To verify our quantification we staged a series or war games simulating an amphibious assault on Petropavlovsk in 1854.

We run separate simulations under three different assumptions:

1) Zero hypothesis: no friendly fire, equal quality of troops for all three sides;

2) Friendly Fire hypothesis: friendly fire probability is close to 0.5 , equal quality of troops for all three sides;

3) Double Strength hypothesis: no friendly fire, Russian troops are of significantly better quality than the Allies. To simulate this difference, Russian soldiers were made to be physically twice as strong and twice as tough as the British and French soldiers. This extra physical strength doubled their probability of disabling (wounding or killing) an enemy in hand-to-hand combat and at the same time halved their probability of being disabled (wounded or killed) both by hand weapons and firearms. These qualities resulted in Russian troops having significantly higher combat effectiveness than the Allies.

The simulations were run until the Allied losses were close to historical numbers. Attrition granularity was equal to 10 in all simulations. 
Results of the simulations are presented in Table 3; simulation results under the Friendly Fire hypothesis are compared with the analytical model prediction in Table 4. Attrition dynamics for the Friendly Fire hypothesis is shown in Figure 2.

Table 3. Results of the wargames under different hypotheses

\begin{tabular}{|l|c|c|c|c|}
\hline \multirow{2}{*}{} & \multicolumn{2}{|c|}{ Allies } & \multicolumn{2}{c|}{ Russians } \\
\cline { 2 - 5 } & Final strength & $\begin{array}{c}\text { Variation from } \\
\text { historical data }\end{array}$ & Final strength & $\begin{array}{c}\text { Variation from } \\
\text { historical data }\end{array}$ \\
\hline Zero hypothesis & 480 & $+1 \%$ & 110 & $-46 \%$ \\
Friendly Fire hypothesis & 480 & $+1 \%$ & 200 & $-2 \%$ \\
Double Strength hypothesis & 450 & $-5 \%$ & 180 & $-12 \%$ \\
\hline
\end{tabular}

Table 4. Distribution of losses by causes under the Friendly Fire hypothesis: simulation and analytical model

\begin{tabular}{|c|c|c|c|c|}
\hline & \multicolumn{2}{|c|}{ Allies } & \multicolumn{2}{|c|}{ Russians } \\
\hline & Simulation & Analytical model & Simulation & Analytical model \\
\hline Artillery fire & $32 \%$ & $\mathrm{n} / \mathrm{a}$ & $\mathrm{n} / \mathrm{a}$ & $\mathrm{n} / \mathrm{a}$ \\
\hline Infantry action & $32 \%$ & $44 \%$ & $100 \%$ & $100 \%$ \\
\hline Losses due to friendly action & $36 \%$ & $56 \%$ & $\mathrm{n} / \mathrm{a}$ & $\mathrm{n} / \mathrm{a}$ \\
\hline Total losses & $100 \%$ & $100 \%$ & $100 \%$ & $100 \%$ \\
\hline
\end{tabular}

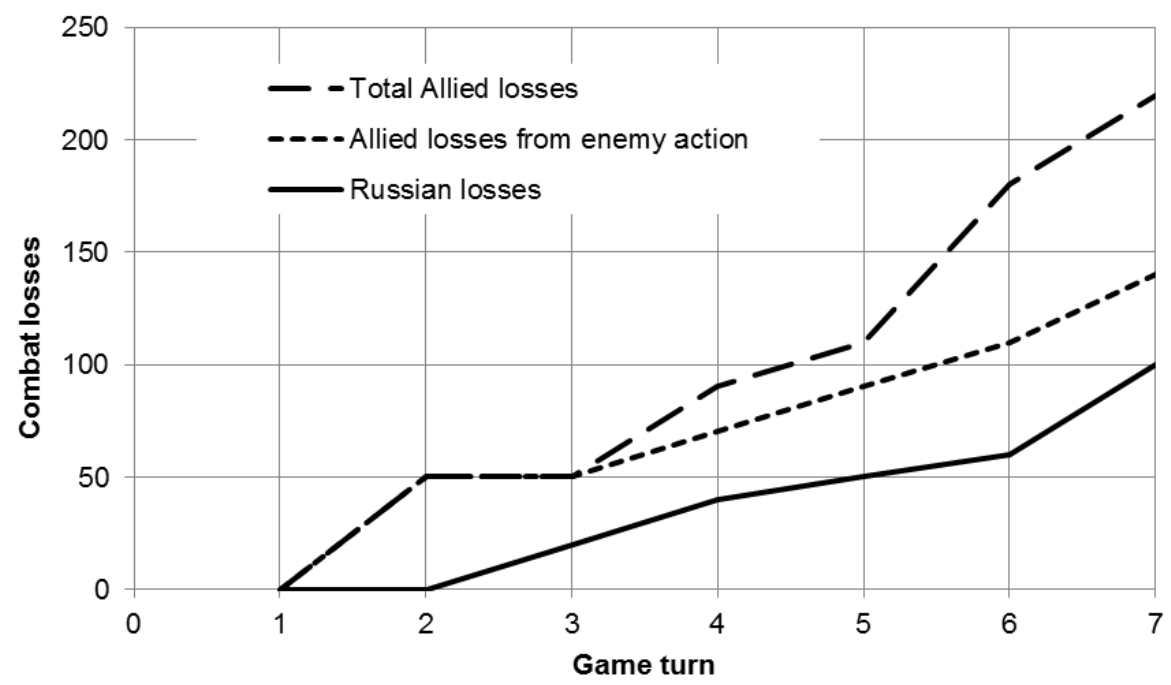

Figure 2. Attrition dynamics in one of the games under the Friendly Fire hypothesis. Allied losses at turn 2 are due to actions of Russian battery № 6. Allies troops entered the bush at turn 3 .

\section{DISCUSSION}

Simulation results under the Zero hypothesis were far from reality, which we interpreted as a strong indication against validity of the hypothesis. From the other side, results under the Friendly Fire hypothesis were close to the historical outcome; therefore we concluded that this hypothesis cannot be rejected. Finally, the Double Strength hypothesis produced results reasonably close to the historical outcome as well; we treated it as a demonstration of unrealistic assumptions one must make to explain the historical results without considering friendly fire.

One may observe that even under the Zero hypothesis the Russians still managed to inflict more casualties on the Allies then suffered themselves. This was a consequence of the initial attack of the British detachment on 
Russian battery №6. In this game, the Allies lost 70 men to Russian artillery fire before retreating into dense bush on Nikolski Hill but failed to inflict noticeable casualties on the Russian side. The dynamics was in general agreement with the historical narrative, except the numbers could not be verified as none of the available sources specified them. Once these initial losses were taken into account, the balance shifted to the Allies' favour as was expected. However we still feel that the effectiveness of Russian field artillery was exaggerated in our simulations; in this particular game, the British commanding officer was able to rally his detachment after losing nearly $60 \%$ of initial strength in one attack, but historical accounts do not mention such an episode.

Under the Friendly Fire hypothesis more than $1 / 3$ of Allied losses were due to friendly fire. Because the analytical model ignored the effect of artillery there was a significant difference in the losses distribution in the simulation game and the analytical model (see Table 4). If the effect of Russian artillery fire was removed from consideration the observed distribution would become much closer to the analytical one with $47 \%$ of losses due to enemy infantry action and $53 \%$ losses due to friendly fire.

We could conclude from the analysis that out of the three considered options the Friendly Fire hypothesis was the only reasonable explanation for the historical battle outcome. To our astonishment, no historical work we consulted cited this factor as the main contributor to the Allied defeat.

\section{CONCLUSION}

We applied our methodology to a study of a historical amphibious operation at Petropavlovsk in 1854 . The Anglo-French assault forces outnumbered the defenders in the ratio 2:1 but still suffered a crushing defeat.

We offered a well-grounded explanation for the anomalous result of the Battle at Petropavlovsk in 1854. Initially we reached our conclusions from studying historical documents; then we tested our hypothesis by building an analytical model and independently by running a series of simulation games. The games also provided us with a valuable insight into the battle dynamics, which was of importance when we compared the analytical and simulation results and checked them against reality as defined in the recorded facts.

In this particular battle we were able to identify and quantify a probable candidate for von Clausewitz frictions which turned out to be friendly fire between British and French troops, causing perhaps nearly the same losses to the Allies as the defender's infantry actions.

We want to highlight that simulation games are a critically important part of this approach used to weight competing hypotheses against each other and against reality. At the same time we would like to caution that these games were not designed to prove some historical truth. Limited time and resources precluded us from using the full potential of this approach. We deliberately restricted our considerations by following the historical plan of attack, changed only a few parameters (probability of friendly fire and overall combat effectiveness) and concentrated on three output variables (British, French, and Russian casualties). We observed that the games provided some insight on how the information available at the time could be used by commanders; as a result the simulation games we played helped us to see several directions of further inquiry: why these friendly fire episodes were so frequent and so devastating, and why the Allied commanders chose the particular plan of attack. We believe that properly designed simulation games are well-suited to investigate these problems, which will be topics for our future research.

Von Clausewitz frictions could be identified and, most importantly, quantified, and in turn the quantification verified if there was enough information on the battle. The proposed approach involves simulation games as a critically important part of the procedure. We would like to emphasise that the simulation games should not aim to reproduce exactly the historical battle; rather it should be used as a tool to study circumstances which produced the historical outcome.

\section{ACKNOWLEDGEMENTS}

The authors thank Marcus Tregenza of Joint and Operations Analysis Division, Defence Science and Technology Group for valuable discussions and suggestions during the work on this paper. O. Pushkarov thanks Prof Anthony Zander, Head of School of Mechanical Engineering of University of Adelaide, and Lachlan Coleman of Engineering Computer and Mathematical Sciences Faculty of the University of Adelaide for their help in securing financial support from the School of Mechanical Engineering, University of Adelaide for attendance of the symposium. 
Kravchuk \& Pushkarov, Modelling a Battle: Looking Beyond Numbers

\section{REFERENCES}

Ashcroft, W.P. (1965). The reminiscences of William Petty Ashcroft - VII. The Naval Review, 53(3), 272278.

Clausewitz, C. von (1984). On War, pp. 732. Princeton University Press: Princeton, NJ

Dupuy, T.N. (1992). Understanding War: History and Theory of Combat, pp. 312. Leo Cooper, London.

Grainger, J.D. (2008). The First Pacific War: Britain and Russia, 1854-1856, pp. 207. The Boydell Press, Woodbridge, UK.

Fesun, N.A. (1860). From the notes of an officer serving on frigate "Aurora". Morskoi Sbornik, 45(1), Unofficial Part, 1-46 (in Russian).

Fowler, B.W. (1995). De Physica Belli: An Introduction to Lanchestrial Attrition Mechanics (3 volumes). Defense Modeling, Simulation and Tactical Technology Information Analysis Center, Huntsville, AL.

Hailly, E. du (1858). Une campagne maritime dans l'Océan-Pacifique. L'Expédition de Pétropavlosk. Revue des Deux Mondes, 16, 686-718 (in French).

Hembold, R.L., and Rehm, A.S. (1995). "The influence of the numerical strength of engaged forces on their casualties” by M. Osipov, Naval Research Logistics, 42(3), 435-490

Lanchester, F.W. (1995). Aircraft in Warfare: The Dawn of the Fourth Arm, pp.244. Lanchester Press, Sunnyvale, CA.

Rath, A.C. (2015). The Crimean War in Imperial Context, 1854-1856, pp. 301. Palgrave Macmillan, New York, NY.

Sabin, P. (2007). Lost Battles: Reconstructing the Great Clashes of the Ancient World, pp298. Hambledon Continuum, London.

Seymour, E.H. (1911). My Naval Career and Travels, pp. 429. E. P. Dutton \& Company, New York.

Stone, I.R., and Crampton, R.J. (1985). 'A disastrous affair': The Franco-British attack on Petropavlovsk, 1854. Polar Record, 22(141), 629-641.

Taylor, J.G. (1983). Lanchester Models of Warfare (2 volumes), Operations Research Society of America, Military Applications Section, Arlington, VA.

The affair at Petropavlovski (1855). O’Burne's Naval Annual For 1855, 89-95.

Zavoiko, V.S. (1954). Report of Kamchatka Military Governor and Commander of Petropavlovski Port to the Manager of the Naval Ministry, № 2453, 7 September 1854. In: Stepanov A.A, Defence of Petropavlovsk, 202-216. Khabarovsk Publishing House, Khabarovsk (in Russian). 